\title{
Conflict Management Strategies Implied by Expected Utility Models of Behavior
}

\author{
CLINTON F. FINK
}

University of Michigan

"Conflict management" usually refers to purposeful control of the overt behavior of parties to a conflict, such that their interactions remain within certain qualitative and quantitative limits. The most frequently specified limits imply the prevention or minimization of violence, but this is not essential to the defintion. Control of the psychological states of the parties (e.g., prevention or minimization of hostility) is often implied, but this is usually seen as one means of controlling behavior, rather than as the main goal. By definition, then, successful conflict management depends on successful control of behavior.

Efforts to control behavior are virtually universal, since most human individuals and groups make frequent or continued efforts to control both their own behavior and the behavior of others. A large proportion of these efforts occurs in or generates conflict situations, and is made by the parties to the conflict as well as by "interested" third parties. It is therefore logically possible for anyone, regardless of his or her role in a particular conflict, to engage in efforts at conflict management.

Unless the "manager" is merely lucky, successful behavior control would seem to depend on two things: knowledge of the 
essential determinants of behavior, and power to mainpulate those determinants. Repeated efforts to control behavior will be successful to the extent that the crucial behavior-determining factors have been correctly identified, and in proportion to the technical feasibility of manipulating those factors in the desired direction. This implies that the long-run reliability of control is a joint (multiplicative) function of knowledge and power: knowledge without power cannot yield control, and power without knowledge can yield control only by accident.

Since there are wide variations among would-be conflict managers in their degree of success, it must be assumed that good luck, knowledge, and power are unevenly distributed, and that those who are repeatedly more successful than others have a larger share of knowledge and power relevant to the behaviors they try to control. In the world of common sense and nonscientific social thought, it is widely held that practical personal experience and favored social position tend to produce higher levels of relevant knowledge and power, and therefore greater success at behavior control and conflict management. In the world of social science, it is widely held that empirically tested formal theories of behavior produce more reliable and communicable knowledge than does personal experience. Those who adopt this position assume that systematic application of such theories will (at least in the long run) yield the most reliably successful conflict management approaches.

This does not imply that all behavior theories are equally useful, since they vary widely in empirical adequacy, generality, and other attributes. Nevertheless, any theory which purports to explain or predict behavior has definite implications for behavior control, since it points to the factors which determine behavior and which therefore would have to be manipulated if one wished to control behavior (assuming the truth of the theory). Different theories have different implications because they conceptualize behavior differently or because they point to different determining factors, or both. Presumably, the theory of model with the greatest empirical validity and the greatest generality will lead to the greatest success in behavior 
control and conflict management. However, it may not be possible to tell which theory has the greatest empirical validity unless it is actually tested through specific control efforts. This suggests that an examination of their behavior-control and conflict-management implications may be useful even before empirical research has produced a definitive choice among competing theories and models of behavior.

The following discussion is restricted to an analysis of the conflict management strategies implied by expected-utility models such as that proposed by Markus and Tanter in this issue's present symposium. Among contemporary theoretical approaches to the analysis of social conflict, perhaps the most widely used are those subsumed under the heading of decision theory, including both statisitcal decision theory (game theory, utility theory, and the like) and allied nonmathematical theories of decision-making. A key concept in the whole panorama of decision theory is the notion of expected utility, defined as the product of the utility of an event times its probability of occurrence. This concept (and its variants such as expected value and subjective expected utility) has been used in many fields for a long time (Miller, 1971) both in normative models of decision-making and in descriptive models which are intended to predict how people will actually behave, usually on the assumption that persons act so as to maximize expected utility. Without delving into the enormous technical literature in this field, the present paper will briefly demonstrate the range and complexity of the alternative strategies of behavior control implied by such models and will point out some of the difficulties and limitations that are likely to be encountered in any attempt to apply them in concrete conflict situations.

\section{GENERAL CHARACTERISTICS OF EXPECTED UTILITY MODELS}

Expected utility (EU) usually refers to a (subjective) utility of an event weighted by its objective probability of occurrence, while subjective expected utility (SEU) merely substitutes a 
subjective (perceived) probability of occurrence in the same formula. The subjective expected utility of an outcome is thus defined as

$$
\operatorname{SEU}_{\mathrm{o}}=\mathrm{p}(\mathrm{o}) \cdot \mathrm{u}_{\mathrm{o}}
$$

where $\mathrm{p}(\mathrm{o})$ is the perceived (subjective) probability that the given outcome will occur and $u_{o}$ is the (subjective) utility of that outcome to the perceiver. Since $p(o)$ can range from 0 to 1 , the range of possible values for $\mathrm{SEU}_{\mathrm{o}}$ is the same as that for $\mathrm{u}_{\mathrm{o}}$, which usually is assumed to vary from some negative value through zero to some positive value, dependeing on the scale one uses for measuring utilities. The above formula can be used in comparing preferences among possible outcomes, but, strictly speaking, it cannot be applied to actions unless one first considers the possible instrumentality of the action in bringing about the outcome. This can be done by defining the subjective expected utility of an action as

$$
\mathrm{SEU}_{\mathrm{a}}=\mathrm{p}(\mathrm{o} \mid \mathrm{a}) \cdot \mathrm{u}_{\mathrm{o}}
$$

where $\mathrm{p}(\mathrm{o} / \mathrm{a})$ is the subjective conditional probability that the outcome will follow if the action occurs. In the simplest case, the subjective expected utility of an action is an attitude-like construct, representing the product of a cognitive orientation, $\mathrm{p}(\mathrm{o} \mid \mathrm{a})$, and an evaluative orientation, $\mathrm{u}_{\mathrm{o}}$, toward a possible outcome of that action.

Most formulas for $\mathrm{SEU}_{\mathrm{a}}$ are actually more complex than this, since they assume that any given action may lead to more than one outcome simulataneously. This leads to the postulation of several distinct utility terms, each with its own probability weight, and these component expected utilities are then summed to arrive at a total SEU. Thus,

$$
\operatorname{SEU}_{\mathrm{a}}=\sum_{\mathrm{o}=1}^{\mathrm{n}} \mathrm{p}(\mathrm{o} \mid \mathrm{a}) \cdot \mathrm{u}_{\mathrm{o}}
$$


where $\mathrm{n}$ is the number of separate outcomes which may simultaneously follow from the action. Although it is not necessary, some models further partition the outcomes in to those with net positive utilities (benefits) and net negative utilities (costs), so that SEU becomes the algebraic sum of subjective expected benefits (SEB) and subjective expected costs (SEC). Thus,

$$
\begin{aligned}
& \operatorname{SEU}_{\mathrm{a}}=\operatorname{SEB}_{\mathrm{a}}-\mathrm{SEC}_{\mathrm{a}} \\
& \mathrm{SEB}_{\mathrm{a}}=\sum_{\mathrm{b}=1}^{\mathrm{n}} \mathrm{p}(\mathrm{b} / \mathrm{a}) \cdot \mathrm{u}_{\mathrm{b}} \\
& \mathrm{SEC}_{\mathrm{a}}=\sum_{\mathrm{c}=1}^{\mathrm{m}} \mathrm{p}(\mathrm{c} / \mathrm{a}) \cdot \mathrm{u}_{\mathrm{c}}
\end{aligned}
$$

where $\mathrm{n}$ is the number of distinct beneficial outcomes (b), where $\mathrm{m}$ is the number of distinct costly outcomes (c), where $u_{b}$ is the (positive) utility of a beneficial outcome, and where $u_{c}$ is the (negative) utility of a costly outcome. Further partitioning of outcomes and utilities into specified classes is often done, but this is usually tied closely to specific empirical applications and can be ignored for the moment.

For explaining or predicting behavior, most SEU models posit a choice (not necessarily conscious or explicit) among two or more actions, types of action, or other distinct behavioral alternatives. Assuming that persons prefer to maximize expected benefits or to minimize expected costs, such models predict that (other things being equal) the alternative with the highest SEU will be chosen. In other words, they predict behavioral choice from a comparison among the actor's overall psychological orientations toward each of the alternatives. Some models go a step further, adding variables other than SEU in order to take into account other determinants of behavior; that is, they specify some of the "other things" that must 
remain equal if behavior is to be reliably predicted from the utility maximization principle. The complexity of such models, and consequently the amount of information needed if one is to use them for predicting behavior in concrete situations, thus varies widely, dependeing on the number of behavioral alternatives which must be considered, the complexity of the formula for SEU, and the number of other behavior determinants which are incorporated in the model.

\section{VIOLENCE PREVENTION AS AN EXAMPLE OF CONFLICT MANAGEMENT}

In order to illustrate the conflict management implications of expected utility models, it will be useful to consider a particular conflict management problem. Virtually any imaginable type of behavior can be considered "conflict behavior," at least under certain circumstances, and its prevention, minimization, or other regulation can be taken as a goal of conflict management. Nevertheless, certain forms of behavior are much more likely than others to be involved in conflict situations, and it is on these that conflict management efforts are usually concentrated. Perhaps the most pervasive goal of conflict managers is to prevent the more violent and destructive forms of conflict behavior, and to maximize the use of nonviolent modes of struggle. This goal is clearly evident, for example, in the following passage:

Man has always had recource to violence. Sometimes this recourse was a mere crime and does not interest us here. But at other times violence was the means resorted to by him who had previously exhausted all others in defense of the rights of justice which he thought he possessed.... This form of violence is none other than reason exasperated. Force was, in fact the ultima ratio. Rather stupidly it has been the custom to take ironically this experession which clearly indicates the previous submission of force to methods of reason. Civilization is nothing else than the attempt to reduce force to being the ultima ratio. We are now beginning to realize this with startling clearness because 'direct action' consists in inverting 
the order and proclaiming violence as the prima ratio or strictly as the unica ratio [Ortega y Gasset, 1932: 82].

This comment epitomizes the widely held view (among social scientists) that instrumental violence is the last resort in most conflicts. It is usually assumed that other means of attaining goals "in the face of human opposition" are tried first, and, only when they fail or at least when it appears that they are destined to fail within acceptable time limits, violent methods of overcoming the resistance of opponents are chosen. Ortega restricts this model of the priorities to revolutionary political struggles, but there is no reason to do so, since the problem of defending one's "rights of justice" can easily arise in relations with another person (especially in situations involving authority relations) just as well as in relations with a government (Simmel, 1955; Dahrendorf, 1959). Furthermore, many violent acts defined as "crimes" are conceptually quite similar to political violence, but on a smaller scale; they take place in situations where at least one party has decided that other methods of goal attainment are less satisfactory.

To view violence as the last resort is to assume that in the early stages of a conflict process, nonviolent methods are preferred by the parties, and that only during the conflict process does their preference for violence become greater. This implies that a process of escalation takes place during the course of the conflict. The problem for the conflict manager thus becomes that of preventing escalation-i.e., of maintaining the conditions under which the parties will continue to prefer nonviolent methods of struggle.

\section{FORMAL EXPLICATION OF VIOLENCE PREVENTION STRATEGIES}

Defined this way, the problem is easily restated in terms of the expected utility models outlined earlier. To take the simplest case, one may distinguish between violent (v) and nonviolent (nv) actions. According to the SEU maximization principle, the general condition for preventing violence is 


$$
\mathrm{SEU}_{\mathrm{v}}<\mathrm{SEU}_{\mathrm{nv}}
$$

Other things being equal, anything that one can do to maintain that inequality for the parties in question will presumably achieve the conflict manager's goal.

If one assumes the escalation process referred to above, it follows that during the course of a conflict there is a tendency for $S E U_{v}$ to increase, or for $S E U_{n v}$ to decrease, or both. Either tendency, if unchecked, will eventually reverse the inequality and lead to violence. The conflict manager thus has two main strategies for preventing violence, which can be used either separately or together. The first aims at lowering or at least preventing further increase in $\mathrm{SEU}_{\mathrm{v}}$, while the second aims at raising or at least preventing further decrease in $S E U_{n v}$. Substrategies under each of these can be defined as efforts to manipulate the various components of SEU, the details of which will depend on the particular equations in the model adopted by the conflict manager.

For example, if one adopts the model given above in equation 4 , the general condition for preventing violence becomes

$$
\left(\operatorname{SEB}_{v}-\left|\operatorname{SEC}_{\mathrm{v}}\right|\right)<\left(\operatorname{SEB}_{\mathrm{nv}}-\left|\mathrm{SEC}_{\mathrm{nv}}\right|\right)
$$

Two main substrategies are then implied for each of the main strategies. In order to raise, lower, or hold constant the SEU of any given action, it is necessary to manipulate or control either the expected benefits or the expected costs of that action, or both. Thus, to lower the $\mathrm{SEU}_{\mathrm{v}}$, one might either lower the expected benefits $\left(\mathrm{SEB}_{\mathrm{v}}\right)$ or raise the expected costs $\left(\mathrm{SEC}_{\mathrm{v}}\right)$ of violence, or both; conversely, to raise the $S E U_{n v}$ one must either raise the expected benefits $\left(S E B_{n v}\right)$ or lower the expected costs $\left(\mathrm{SEC}_{n v}\right)$ of nonviolence, or both. The requirements are parallel if one is merely trying to maintain an existing $S U_{v}$ against its conflict-induced tendency to increase or to maintain an existing $S_{E U_{n}}$ against its conflict-induced tendency to decrease. 
If one then substitutes the formulas for SEB and SEC as given in equations $4 a$ and $4 b$, the condition for preventing violence becomes

$$
\begin{aligned}
& {\left[\sum_{b=1}^{n} p(b \mid v) \cdot u_{b}-\left|\sum_{c=1}^{m} p(c \mid v) \cdot u_{c}\right|\right]<} \\
& {\left[\sum_{b=1}^{n} p(b \mid n v) \cdot u_{b}-\left|\sum_{c=1}^{m} p(c \mid n v) \cdot u_{c}\right|\right]}
\end{aligned}
$$

This generates two further possibilities within each substrategy. The subjective expected benefits or costs of an action are defined as the algebraic sums of the products obtained by multiplying the magnitude (perceived utility, $u_{b}$ or $u_{c}$ ) of each identifiable positive or negative consequence of that action (perceived benefits or costs) by the perceived probability that the given action will lead to that consequence. To increase the magnitude of a given product, one may either raise the magnitude of the utility term or raise its associated subjective probability, or both. Conversely, to decrease the magnitude of a given product, one may lower either the utility or the probability, or both. The requirements are parallel if one wishes to hold SEB or SEC constant against their autonomous or conflict-induced tendencies to change.

The conflict management strategies implied by this formulation can thus be summarized as a series of altemative means by which, throughout the course of a given conflict, the parties can be kept in the state of preferring nonviolent methods of struggle over violent methods. Eight classes of logically manipulable variables have been postulated, each of which defines a strategic intervention point. To keep the $\mathrm{SEU}_{\mathrm{v}}$ lower than the $\mathrm{SEU}_{\mathrm{nv}}$, the manager may try any or all of the following:

I. To decrease (or prevent the increase of) $\mathrm{SEU}_{\mathrm{v}}$

A. Decrease (or prevent the increase of) $\mathrm{SEB}_{v}$, by either 
1. lowering or holding constant the perceived benefits of violence, or

2. lowering or holding constant the subjective probabilities of those benefits;

B. Increase (or prevent the decrease of) $\mathrm{SEC}_{\mathrm{v}}$, by either

1. raising or holding constant the perceived costs of violence, or

2. raising or holding constant the subjective probability of those costs.

II. To increase (or prevent the decrease of) $\mathrm{SEU}_{\mathrm{nv}}$

A. Increase (or prevent the decrease of $\mathrm{SEB}_{\mathrm{nv}}$, by either

1. raising or holding constant the perceived benefits of nonviolence, or

2. raising or holding constant the subjective probability of those benefits;

B. Decrease (or prevent the increase of) $S E C_{n v}$, by either

1. lowering or holding constant the perceived costs of nonviolence, or

2. lowering or holding constant the subjective probability of those costs.

Within these eight specific strategies (IA-1, IA-2, .., IIB-2), numerous additional subtypes could be generated by making further distinctions among specific classes of benefits and costs. For example, one could subdivide benefits and costs into three main categoreis: (a) the intrinsic rewards and punishments involved in performing a given action; (b) the gains or losses that result from a given action that are directly related to the goals or values at issue in the conflict; and (c) the secondary gains or losses which are not directly related to the issues but which may be regarded as positive or negative side effects of the particular action. But this is only one of many ways that additional management strategies could be defined, given the various ways in which expected utility models can be further elaborated. At this point, examination of these other logical possibilities is not essential, so long as one keeps in mind that the eight strategies discussed here by no means exhaust the topic of conflict management, or even that of violence prevention in the limited case postulated here. For present purposes, it will be more useful to explore the possible empirical and practical meanings of these few abstract categories. 


\section{EMPIRICAL INTERPRETATION}

In attempting to bring the above strategies into some sort of reasonable contact with empirical social reality, one may interpret them either at a very general level or in terms of specific cases. The general level seems more appropriate here, since these strategies are potentially relevant to a wide variety of concrete conflict situations. However, some specific cases will be cited in order to illustrate certain general points. It must be remembered, as mentioned earlier, that attempts to minimize or prevent violence may be made either by the parties themselves or by third parties, such as relatives, friends, neighbors, professional counselors or mediators, social service agencies, or private and governmental agencies of all kinds. Furthermore, while any of these potential conflict managers may in principle use any of the strategies discussed here, selective constraints may be imposed by the specific characteristics of concrete conflict situations, and by the resources available to particular managers.

The problem of manipulating the pertinent cognitive and evaluative orientations of real persons or groups is enormously complex and does not lend itself to any simple social technology. What Harold Lasswell (1931) said of conflict in general is also true of conflict management-i.e., that it may involve use of the whole range of available instrumentalities for social control, from simple, noncoercive verbal means through the most coercive manipulations of rewards, punishments, or environmental parameters. Indeed, much that goes under the heading of social control is in fact conflict management, and although it is not usually conceived in expected utility terms, there are nevertheless many familiar methods of social control or social influence which might be employed in the various strategies of violence prevention outlined above.

\section{MINIMIZING THE ATTRACTIVENESS OF VIOLENCE}

Strategy I-A focuses on lowering or minimizing the expected benefits of violence. This bears directly on a central considera- 
tion in the choice between violent and nonviolent methodstheir relative instrumentality for goal attainment in conflict situations. The most common argument in favor of violence is its greater effectiveness for overcoming, circumventing, or otherwise neutralizing the opponent so that one may attain one's goal (or at least some acceptable compromise). Strictly speaking, such arguments focus on the subjective probability terms-formally, they say that $p(b \mid v)>p(b \mid n v)$-since to say that an action is more effective is to say that it is more likely to lead to a specific desired outcome. An attempt to counter this perception would thus fall more precisely under strategy IA-2.

Even without the exhaustion of nonviolent alternatives implied by the escalation process, there are often strong cognitive supports for the belief that violence is quite effective. In many situations, violence can readily eliminate the opponent, reduce his capability of pursuing his goals or of interfering with one's own, or reduce his willingness to continue active opposition. It is therefore difficult in these situations for a conflict manager to counteract the belief in the efficacy of violence. However, such situations are not universal, and violence can sometimes be seen as ineffective. There are many kinds of issues in conflict situations, especially those having to do with the relations between the parties, where some uses of violence automatically preclude goal attainment. The obvious example is that of eliminating the opponent: if one wishes to establish a specific relationship with a reluctant partner (e.g., marriage, servitude, and the like), murdering the partner will not help. In such situations, where violence is obviously self-defeating, there is strong cognitive support for the belief in its ineffectiveness.

The crucial task for the conflict manager is to lower the perceived effectiveness of violence (strategy IA-2) where the parties have some reason to believe that it would succeed. One way to do this would be to show the violence-prone party that it has overestimated its own strength (or underestimated the strength of the opponent), so that engaging in a fight would be fruitless. Advice to small minorities or to much weaker parties 
in general often seems to have this aim, as in the frequently heard countermilitant argument that the black population in the United States is so overwhelmingly outnumbered by the white population that it could never achieve its aims through insurrection. Another approach would be to set up new defenses that are more impervious to violent attack and show the violence-prone party that these defenses are adequate to render violent action ineffective. Fortresses, walls, and security systems of many kinds have the aim of rendering attacks less effective and may be veridically perceived as making futile certain forms of violence that might otherwise be chosen. A third approach would be to create a situation in which the use of violence automatically reduces or eliminates any chance of attaining the goal. Many rules of competitive sports which penalize or disqualify one for certain acts of violence against one's opponent seem to have this character, as do rules disqualifying one for insurance benefits if one commits arson or murder.

It is also possible to reduce the expected benefits of violence by lowering or minimizing the utility term, $u_{b}$ (strategy IA-1). One way to do this is to show that violence would partly destroy the goal object, thus necessarily reducing its value even though ensuring its attainment. For example, one might argue that a violent struggle could not be kept within bounds, so that desired property might be damaged unintentionally in the process of wresting it from the opponent. Another approach, for situations in which the goal involves some sort of behavioral compliance by the opponents, is to show that victory through violence would yield less-satisfactory performance than anticipated. For example, slave-owners, supervisors, educators, jailors, and other captors inclined to use corporal punishment to stimulate performance are often advised that such techniques, while leading to overt compliance, actually produce a decrement in performance, especially as compared with other available techniques.

While the above strategies may be regarded as forms of deterence, that term is usually reserved for strategy IB, which 
focuses on raising or maximizing the expected costs of violence. The primary means of cost-oriented deterrence is through threats of retaliation or punishment, and it is widely used by parties to a conflict against their opponents. It is also widely used by third parties in international situations (Russett, 1963; Fink, 1965; Dowty, 1972), in a wide range of governmental control efforts such as those embodied in the criminal code, and in many other situations.

One may readily identify strategy IB-1 (raising the perceived costs of violence, $u_{c}$ ) with explicit efforts to manipulate the magnitude of the threatened punishment or retaliation. Similarly, strategy IB-2 (raising the perceived likelihood of incurring those costs) is recognizable in efforts to increase the credibility of a deterrent threat, which involve manipulation of the probability term, $\mathrm{p}(\mathrm{c} \mid \mathrm{v})$. The popularity of cost-oriented deterrence among conflict managers is reflected in the vast literature about it, and the ease of identifying it with these formally defined strategies is reflected in the frequent use of expectedutility formulations by students of deterrence.

The popularity of deterrent threats is linked to the widespread belief in the efficacy of violence. In strategy IB-2, the conflict manager is in a position analogous to that of any violence-prone party in a conflict. But there are deterrents to the use of deterrence which may inhibit conflict managers from adopting it. First, there is something paradoxical about using the threat of violence (and occasional actual violence to give the threat credibility) in order to deter violence. To the extent that this is effective in the hands of a third party (i.e., the state or other social control agencies), it will necessarily work against lowering the perceived effectiveness of violence (strategy IA-2) in the conflict the manager is trying to control. So long as the threat of violence is perceived to work in some situations when used by some people, this perception will be generalized and applied to other situations and other people. Second, deterrence may be ineffective in the long run because it is difficult to justify strong deterrent threats against nonviolent actions which may lead to violence. For example, the criminal code is uneven 
in this respect because, while it may attempt to deter the use of some nonviolent verbal means such as blackmail and slander, it does little (except in rare instances) to deter the use of threats of violence or of milder forms of violence such as corporal punishment, even though these may often lead directly to escalation in particular conflict situations. Finally, there are built-in limitations of deterrence due to the difficulty and high cost of making deterrent threats credible. For example, one reason why capital punishment does not prevent murder is that the probability that it will be used is relatively small, even in the most repressive regimes. There is always a good chance of not getting caught, of not getting convicted, of escaping, or of getting a reprieve or commutation of sentence, and the task of credibly reducing the probability of each of these outcomes is massive. The same is true for the whole range of lesser and nonviolent sanctions that the criminal code applies.

There are other examples of strategy IB which do not encounter these difficulties, because they do not use threats as a means of deterrence. Instead, they rely on warnings of unanticipated dangers. Thus, one form of strategy IB- 1 is to heighten the violence-prone party's awareness of the negative side effects of using violence. This is certainly feasible in the case of extreme violence, since there may be positive reasons for wanting the opponent to remain alive and functioning. Eliminating or seriously crippling the opponent, if it is merely a means of preventing him from doing certain things that you do not want him to do, has the disadvantage that it also prevents him from doing other things that you might want him to do. Elizabeth Converse (1968) has described this as the imprecision of violence, which is one of the major drawbacks of at least certain forms of violence, and perhaps also of other means of social control. Another variant of this strategy is to heighten awareness of the intinsic costs of violence, by showing that one cannot use it without suffering psychological or physical damage in the process. Admonitions about backfire effects, such as those risked in chemical, biological, and nuclear warfare, are a case in point. 
MAXMMIZING THE ATTRACTIVENESS OF NONVIOLENCE

On the other side of the inequality, conflict management focuses on the subjective expected utility of nonviolent methods. Strategy IIA aims to raise or maximize the expected benefits of nonviolence, while strategy IIB aims to lower or minimize its expected costs.

Strategy IIA-2 deals with the key issue concerning nonviolent means, namely their perceived effectiveness in goal attainment, represented by the probability term $p(b \mid n v)$. This has been one of the central problems for political and religious groups promoting nonviolent ideologies of social action, especially among parties who feel that they have exhausted the available nonviolent alternatives against an intransigent enemy.

Cognitive support for belief in the ineffectiveness of nonviolent methods is often quite strong. For example, the notorious lack of equality in the administration of justice for the poor and for minority groups becomes widespread knowledge in a variety of ways, and leads to a general discrediting of law enforcement and jurisprudence among the chronically defeated. Widespread dissemination of statistical evidence for such patterns of discrimination can strengthen the perception of the opponents' intransigence and lead to reduced confidence in institutionalized nonviolent methods of struggle (Tumin, 1968). More generally, the members of a society develop stable expectations about the likelihood of a satisfactory settlement if they employ particular nonviolent methods or institutionalized mechanisms of conflict resolution. These expectations, based on accumulated experience and common knowledge, will usually be different for different parties and between different societies. Thus it is clearly possible for certain nonviolent modes of conflict resolution to be seen as ineffective in one group or society but quite effective in another (Nader and Metzer, 1963). This indicates that conflict management efforts directed at increasing confidence in nonviolence may be feasible in some instances.

Such efforts can be made in a variety of ways. One approach is to expand the violence-prone party's awareness of and 
competence in the use of nonviolent techniques, ranging from more effective techniques of persuasion to more effective techniques of noncooperation (boycotts, strikes, ostracism, and the like) or more sophisticated methods of bargaining and conflict resolution. This can be done through educational programs, the dissemination of research findings on these methods, actual mass demonstrations, and the like. A second approach is to make available certain agencies or institutionalized mechanisms which were previously unavailable or to upgrade the effectiveness of existing mechanisms. The spread of new forms (e.g., ombudsman roles, third party consultation, sensitivity training, and encounter groups) and the reform of existing institutions (e.g., extending the vote, changing criteria for jury composition, or reducing bureaucratic red tape) are typical examples.

These and other approaches to increasing the perceived effectiveness of nonviolence share a potentially self-defeating quality, similar to the paradox of deterrent threats discussed earlier. This strategy runs the risk that as one increases the weaker party's awareness of or belief in the effectiveness of nonviolent means against the opponent, one may automatically reduce the opponent's belief in their effectiveness for his own goal attainment, thus inducing the opponent to consider violent alternatives. This results from the fact that one can hardly improve the weaker party's perceived chances of winning without altering the perceived and actual power relations between the parties. The violent response of some Southern segregationists, once the integration forces had won their case in court, illustrates this potential for a violent counterrevolution following a successful nonviolent revolution.

Strategy IIA-1 avoids this paradox since it focuses on raising or maximizing the perceived utility $\left(\mathrm{u}_{\mathrm{b}}\right)$ of nonviolence. Since this is parallel to strategy IA-1, one might simply apply the examples there in reverse. However, it seems less feasible to argue that nonviolence would somehow improve the goal object than it does to argue that violence might damage it. The conflict manager might have an easier time persuading the violence- 
prone party that the longer-range benefits of winning the short-run goal nonviolently are larger than he might imagine. Or the extra prestige accorded one who plays by the rules and struggles honorably may be a credible inducement in many cases.

Strategy IIB is the reverse of deterrence, since it focuses on reducing the expected costs of nonviolence. The key problem here is that nonviolence will be seen as costly to the extent that it makes one vulnerable to defeat by a violent opponent. But this aspect is already taken care of in strategy IIA, which seeks more effective nonviolent means of struggle. There are other costs, however, that may vary independently of the effectiveness of nonviolence.

In strategy IIB-1, the conflict manager's aim is to lower or prevent an increase in the perceived costs $\left(u_{c}\right)$ of nonviolent action. There are certainly many examples of nonviolent means which, though effective, are quite expensive to employ. Surveillance, propaganda campaigns, legal procedures, and other techniques and mechanisms may be cheaper than violence in some situations, but they require time and effort which may make them prohibitively expensive in other situations or for some parties. Finding more efficient ways of using them, or modifying institutions so that they become chaper to use, is one general way of reducing their perceived costs. The establishment of streamlined procedures, as in small claims courts, is an example. This approach may actually be an essential part of making certain nonviolent means more widely available. Another approach would be to remove negative sanctions which currently exist against some forms of nonviolence. Thus, legitimation of forms of protest currently regarded as dishonest, unscrupulous, unpatriotic, or illegal would effectively lower their perceived costs. Modification of norms which regard the preference for nonviolence as "cowardly" or "unmanly" would also come under this approach.

Finally, strategy IIB-2 aims to reduce the subjective probability of incurring such costs, $p(c \mid n v)$. This implies reducing the credibility of existing deterrents to nonviolence. One approach 
is to show that certain sanctions, though threatened, are rarely applied. Thus, disseminating information concerning the rarity with which certain laws are invoked, or concerning the frequency of suspended sentences or amnesty for certain kinds of illegal nonviolent acts, could help reduce the perceived risk of those actions. Another approach would be to argue that there is little chance of having to incur the whole cost of an apparently expensive technique, because its initiation usually induces a more rapid resolution of the conflict. For example, one party may be persuaded to initiate a lawsuit on the assumption that the opponent will prefer to reach a settlement out of court rather than incur the costs of a lengthy legal battle.

\section{ADVANTAGES AND LIMITATIONS OF EXPECTED UTILITY MODELS}

The above examples are sufficient to show that conflict management strategies implied by expected utility models do correspond to meaningful and socially significant empirical phenomena. Although the examples adduced are by no means exhaustive and may not be the best ones possible, their selection and formulation were definitely facilitated by the specific model presented in equations 1-7, given the particular conflict management problem posed (violence prevention). This indicates that such models have, at the very least, some degree of heuristic value for practical applications.

Other indications of heuristic value are found in the analytic advantages of the expected utility formulation. First, it provides a parsimonious classification scheme which serves as a relatively powerful organizing framework for thinking about diverse empirical elements relevant to conflict management. Second, it has sufficient precision and internal consistency to facilitate scrutiny of the interdependence and mutual implications of the alternatives while searching for the best procedure to use in a particular case. Third, it provides a rational framework which is capable of incorporating both rational and irrational elements in behavior. Fourth, it is an "open" model in the sense that it 
readily permits the proliferation of distinctions where necessary and the recombination of elements in a variety of ways, thus rendering it useful in many different kinds of situations. And finally, it is capable of coherent articulation with ethical and other considerations that must enter any attempted applications.

Despite these advantages, expected utility models have serveral limitations which must be kept in mind in considering their use by conflict managers. First, they clearly allow much greater analytic precision than current levels of empirical measurement and practical technique can fully exploit. Since very precise measurement of the psychological states corresponding to subjective probability and utility is difficult, especially in ongoing conflict situations, application of the models can be fruitless or counterproductive if the manager tries to work within the close tolerances they allow in the abstract, or if he fails to assign sufficiently large error estimates to the empirical data. Second, expected utility models are insufficient by themselves to suggest specific techniques of conflict management. They must be imbedded in larger theories or bodies of empirical knowledge which provide some purchase on the problem of measuring and controlling the relevant psychological states. Third, such models have blind spots concerning psychological processes which may be of great value in conflict management. Since they are best suited to the analysis of psychological reactions to existing alternatives, they run the risk of diverting attention away from psychological processes, such as creative problem-solving, which could, if fully exploited, eliminate much of the work for conflict managers in the long run.

\section{CONCLUDING REMARKS}

This paper has explored the implications of one kind of expected utility model for one kind of conflict management problem (violence prevention under conditions of potential 
escalation). The analysis has been conducted at relatively high levels of abstraction and generality, and no effort has been made to provide guidance for particular conflict managers in particular conflict situations. It has been an exercise in heuristic modelling and will have fulfilled its purpose if it suggests fruitful lines of inquiry or useful modes of analysis.

Similar analyses can be performed on other expected utility models, such as the one proposed by Markus and Tanter earlier in this issue. These will differ in many details and will undoubtedly lead to many examples quite different from the ones adduced here. Comparisons among the practical implications of various expected utility models may be of great value in identifying crucial gaps or ambiguities in the models and in identifying crucial points of complementarity or of disagreement among various conflict management approaches. Such analyses should be expanded so as to do justice to the voluminous literature on violence, nonviolence, and violence prevention which has only been hinted at here. The analysis and comparisons should then be extended to other kinds of conflict management problems and to other classes of behavioral models. These extensions might help identify points of articulation, disagreement, and compatibility among a wider set of theories, models, and practical approaches. A concerted effort to confront formal models (and unformalized theories) with their empirical and practical implications and limitations would be of great benefit, not only to conflicting parties and conflict managers, but also to those who are primarily interested in advancing basic research and theory about social conflict.

\section{REFERENCES}

CONVERSE, E. (1968) "The war of all against all: a review of the Journal of Conflict Resolution, 1957-1968." J. of Conflict Resolution 12 (December): 471-532.

DAHRENDORF, R. (1959) Class and Class Conflict in Industrial Society. Stanford, Calif.: Stanford Univ. Press. 
DOWTY, A. (1972) "The application of international guarantees to the Egypt-Israel conflict."J. of Conflict Resolution 16 (June).

FINK, C. F. (1965) “More calculations about deterrence." J. of Conflict Resolution 9 (March): 54-65.

LASSWELL, H. D. (1931) "Conflict, social," pp. 194-196 in E. R. Seligman and A. Johnson (eds.) Encyclopedia of the Social Sciences, Volume IV. New York: Macmillan.

MILLER, G. A. (1971) Mathematics and Psychology. New York: John Wiley.

NADER, L. and D. METZER (1963) "Conflict resolution in two Mexican communities." Amer. Anthropologist 65 (June): 584-592.

ORTEGA Y GASSET, J. (1932) The Revolt of the Masses. New York: W. W. Norton. RUSSETT, B. M. (1963) "The calculus of deterrence." J. of Conflict Resolution 7 (June): 97-109.

SIMMEL, G. (1955) Conflict and the Web of Group Affiliations (K. H. Wolff and R. Bendix, translators). New York: Free Press.

TUMIN, M. (1968) "Some social consequences of research on racial relations." Amer. Sociologist 3 (May): 117-124. 